\title{
IMMEDIATE EFFECT OF CALCANEAL TAPING VERSUS WINDLASS TAPING ON CALCANEAL ANGLE IN SUBJECTS WITH PLANTAR FASCIITIS
}

\author{
N.C. Aishwarya*, K. Venkata Sai \\ SIMS College of physiotherapy, Guntur, Andhra Pradesh, India
}

\begin{abstract}
Background: Plantar fascia is often thought to develop from excessive stress on plantar fascia which is caused due to abnormal foot biomechanics. Taping is widely used intervention to correct the faulty biomechanics. This study aims at comparing the effects of calcaneal taping technique and windlass taping technique where the former corrects the biomechanics at rear foot and the latter at forefoot. Material and methods: This study was done out on sixty subjects with unilateral plantar fascia symptoms of age group 22- 60 years. Random allotment was done into both groups. Both groups were assessed for calcaneal angle and pain intensity before and immediately after the tape application in bilateral stance. Results: Pre-post comparison showed reduced calcaneal eversion angle and pain intensity in both groups. However, this reduction was not significant. Between-groups analysis showed significant reduction of calcaneal eversion angle in calcaneal taping group $3.4\left(95 \% \mathrm{Cl}=-4.52\right.$ to $\left.-2.42^{\circ}\right)$ than windlass taping group. Reduction in pain intensity in calcaneal taping group was $20.7(95 \% \mathrm{Cl}=-30.61$ to -10.72$)$ greater than in windlass taping group. Conclusion: Calcaneal taping provided better relief of symptoms with better biomechanical correction in short term when compared to windlass taping technique.
\end{abstract}

Keywords: Plantar fasciitis, Windlass, Taping, Calcaneal angle.

\section{INTRODUCTION}

Plantar fasciitis is a degenerative syndrome of plantar fascia resulting from repeated trauma at its origin on the calcaneus. Plantar fasciitis is reported to be the most common cause of inferior heel pain in adults [1]. Other names for plantar fasciitis include but are not limited to painful heel syndrome, heel spur syndrome, runner's heel, calcaneodynia and calcaneal periostosis' The word 'fasciitis' assumes inflammation as an inherent component of this condition. Recent research suggests that some presentations of plantar fasciitis manifests noninflammatory, degenerative process and should more aptly termed as 'plantar fasciosis'[2]. In India more than 1 million individuals are treated for plantar fasciitis on an annual basis. Plantar fasciitis affects individuals regardless of sex, age, ethnicity, or activity level. The affected population includes physically active individuals such as runners, military personnel and general sedentary adults of age 40-60 years [3]. The role of plantar fascia is twofold - to provide support of the longitudinal arch and to serve as a dynamic shock absorber for the foot and entire leg. There are various predisposing factors for

*Corresponding author:

Email: ncaishwarya6@gmail.com

http://dx.doi.org/10.20530/IJTA 33 28-32

ISSN 2320-138X @ 2016 development of plantar fasciitis, among which 81$86 \%$ of individuals were observed to have excessive pronation of foot which is caused by plantar flexion and adduction of the talus during weight bearing, causing the calcaneus to evert. The biomechanics of an adducted talus and everted calcaneus results in increased tension in the structures on the plantar surface of the foot, causing arch to collapse and create excessive tensile strain within the plantar fascia and produce microscopic tears and chronic inflammation [4, 5]. There are various non-surgical interventions available for management of plantar fasciitis. These include but are not limited to antiinflammatory drugs, electrotherapy modalities (iontopheresis, ultrasound, and extra corporeal shockwave), exercise therapy (stretching, massage), manual therapy (joint and neural mobilizations) and external support (orthotic devices and taping). Most of the above treatments resolve the symptoms produced by plantar fasciitis, whereas orthotics and taping aim at improving the poor biomechanics of foot $[6,7]$. Calcaneal angle measurement is the most widely used biomechanical measure for evaluation of foot position. The biomechanics of the faulty foot can be corrected either at rearfoot, midfoot or at forefoot region using various taping techniques [8]. Windlass taping technique is a modification of low dye taping which addresses the biomechanical factors at forefoot [9]. Calcaneal taping technique addresses the faulty biomechanics at the rear foot [10]. Both these techniques when used separately 
have shown significant relief of plantar fascia symptoms but there are no studies comparing the effect of these taping techniques on biomechanical measures of foot. Therefore, the purpose of this study is to compare the effects of calcaneal taping versus windlass taping techniques on the calcaneal eversion angle in static standing along with pain in subjects with plantar fas ciitis.

\section{MATERIALS AND METHODS}

The selection of the subjects was done with convenience sampling method utilizing eligibility criteria. The inclusion criteria were (1) age between 22 and 60 years, (2) pain located at the heel or plantar surface of midfoot (3) pain with first steps upon walking after prolonged rest and (4) presence of an everted calcaneus greater than or equal to $2^{\circ}$ (goniometric measurement) The exclusion criteria were (1) congenital deformity of the foot or ankle, (2) history of ankle or foot fracture, (3) previous surgery or treatment for plantar fasciitis in the previous 6 months (4) use of an assistive device for ambulation, (5) bilateral plantar heel pain, and (6) refusal to participate in the study. Sixty participants who met the eligibility criteria were assigned randomly to either calcaneal taping group or windlass taping group. All participants were explained about the study and were asked to sign on consent form approved by SVIMS institutional ethical committee. Calcaneal taping was done using athletic tape which was cut into four parts. First strip was applied distal to the lateral malleolus, pulling the calcaneus medially, and attached to medial aspect of the foot, distal to the medial malleolus. Second and third strip followed the same pattern with overlap of approximately one third of the tape width moving in the distal direction. Fourth strip went around the back of the heel starting distal to the lateral malleolus, wrapping around the posterior aspect of the calcaneus and anchoring distal to the medial malleolus (Fig 4). Windlass taping was done using athletic tape where in 2 or 3 anchor strips were applied under the metatarsal heads starting from first to fifth metatarsal. Participants were asked to actively extend the great toe and evert the forefoot. 2 strips were applied overlapping one another from first metatarsal head around heel, 2 strips were applied overlapping each other from fifth metatarsal head around heel. To close with, a wider strip was wrapped around starting from dorsomedial aspect of first metatarsal to dorsolateral aspect of fifth metatarsal head (Fig 3).

For all the participants calcaneal eversion angle and pain intensity were measured using universal goniometer and Visual Analogue Scale (VAS) respectively, before and after application of tape. Calcaneal eversion angle was measured using universal goniometer in relaxed bilateral stance as the acute angle between the leg and calcaneal bisection lines [11]. The pain during walking was measured using VAS scale. The data was analyzed using student's unpaired t-test at $5 \%$ level to detect the significance of differences between the two groups. The data entry and statistical analysis was done utilizing MS-Excel and SPSS software.

\section{RESULTS}

Baseline demographic and clinical characteristics of participants in both the groups were given in Table 1. Both the groups were homogenous at baseline.

Between the groups analysis showed reduction of pain intensity and calcaneal angle immediately after application of tape in both groups(Table 2). However, the reduction in calcaneal eversion angle in calcaneal taping group was $3.4(95 \% \mathrm{Cl}=-4.52$ to $\left.2.42^{\circ}\right)$ greater than windlass taping group. Reduction

Table 1 : Comparison of subjects' characteristics at baseline by group.

\begin{tabular}{lccc}
\hline Subject characteristics & Calcaneal taping group & Windlass taping group & pvaluet \\
\hline AGE $(\mathrm{Yrs})^{\ddagger}$ & $37.13 \pm 7.29$ & $41.33 \pm 6.21$ & .10 \\
Gender (F/M) & $17 / 13$ & $18 / 12$ & .79 \\
VAS score $(\mathrm{mm})^{\ddagger}$ & $7.27 \pm 1.03$ & $7.40 \pm 0.99$ & .72 \\
Calcaneal eversion angle $_{(\text {degree })^{\ddagger}}$ & $10.80^{\circ} \pm 1.42$ & $11^{\circ} \pm 1.13$ & .67 \\
\hline
\end{tabular}

$\ddagger$ Values expressed as Mean \pm SD

+ The level of significance was set at $p<0.05$ 
Table 2: Comparison of outcome values in both groups at Pre and Post Experimental Evaluations

\begin{tabular}{lcccc}
\hline Outcome/Evaluation & $\begin{array}{c}\text { Calcaneal taping } \\
\text { group }\end{array}$ & $\begin{array}{c}\text { Windlass taping } \\
\text { group }\end{array}$ & 95\% Cl of difference & pvaluet \\
\hline Calcaneal angle (Pre) $^{\ddagger}$ & $10.80 \pm 1.42^{\circ}$ & $11 \pm 1.13^{\circ}$ & -1.16 to $0.76^{\circ}$ & .67 \\
Calcaneal angle (Post) $^{\ddagger}$ & $6.40 \pm 1.50^{\circ}$ & $9.87 \pm 1.30^{\circ}$ & -4.52 to $-2.42^{\circ}$ & $<0.0001$ \\
VAS (Pre) $^{\ddagger}$ & $72.67 \pm 10.33$ & $74.0 \pm 9.86$ & -8.88 to 6.22 & .72 \\
VAS (Post) $^{\ddagger}$ & $34.67 \pm 15.06$ & $55.33 \pm 11.25$ & -30.61 to -10.72 & .0002 \\
\hline
\end{tabular}

$\ddagger$ Values expressed as Mean \pm SD

+ The level of significance was set at $p<0.05$

Figure.1 Comparison of VAS score at pre \& post evaluations in both groups

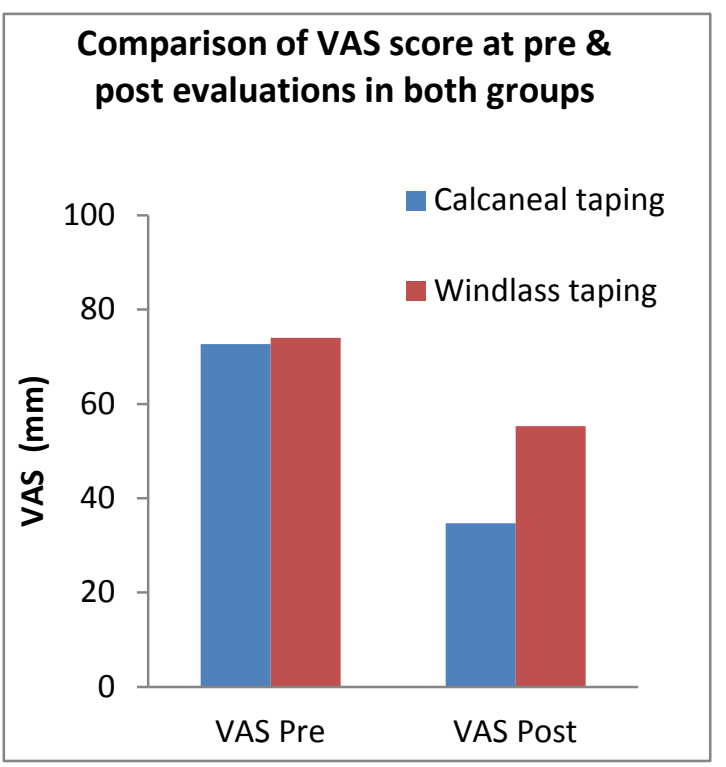

in pain intensity in calcaneal taping group was 20.7 $(95 \% \mathrm{Cl}=-30.61$ to -10.72$)$ greater than windlass taping group. No adverse effe cts of treatment were reported.

\section{DISCUSSION}

The results obtained in this study show that calcaneal taping has greater beneficial effect on reduction of pain and calcaneal eversion angle than windlass taping in subjects with plantar fasciitis (Fig 1 \& 2). In plantar fasciitis, the cause of pain during weight bearing activities can be attributed to over pronation of foot and medial arch flattening leading to excessive stress on plantar fascia [12, 13]. Biomechanically, over pronated foot can lead to flattening of medial arch or vice versa. Both the taping techniques used in this study did not directly
Figure.2 Comparison of calcaneal angle at pre \& post evaluations in both groups

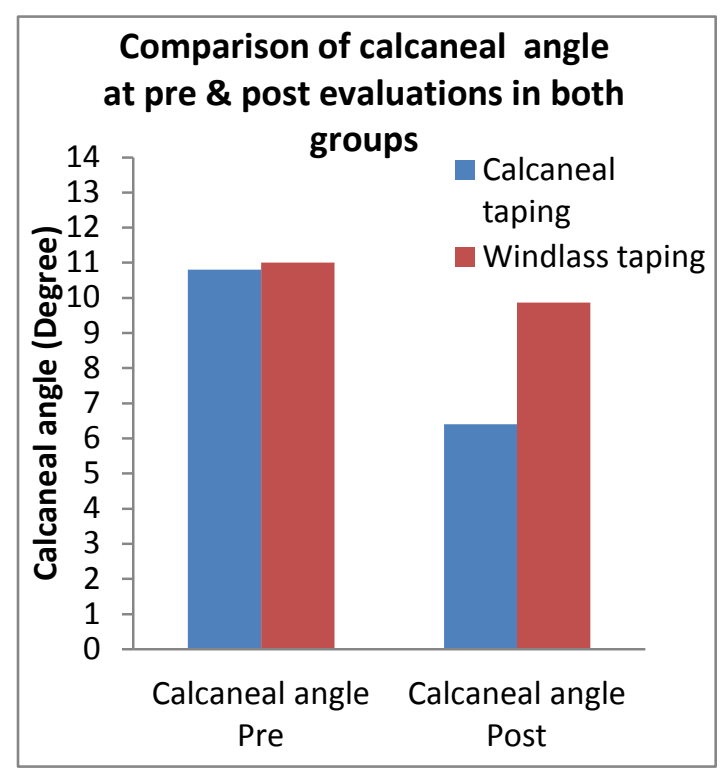

support the medial arch but rather aimed at correcting the over pronation of foot either at rear foot or at forefoot which in turn led to raise of medial arch. Windlass taping technique utilizes the arch raising effect of metatarsophalangeal joint extension. The extension of the toes pulls the plantar aponeurosis around the head of metatarsals causing tension and raise of medial arch. The raise of medial arch decreases the subtalar pronation which is reflected by reduction in calcaneal eversion angle. In calcaneal taping the biomechanical correction is done at rear foot. This technique corrects the calcaneal eversion and places it near to neutral which leads to increase in the height of medial longitudinal arch. This results in reduced tensile force on the plantar fascia which reduces microscopic tears and inflammation. The better 
Figure 3. Windlass taping

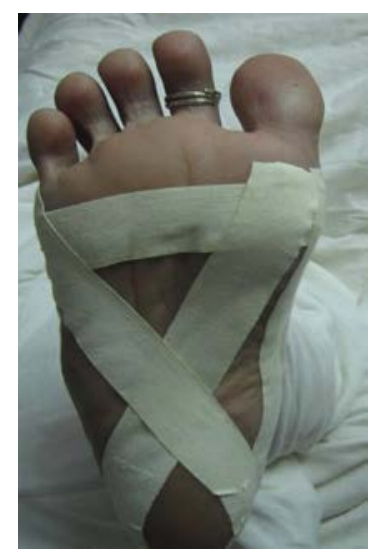

effect of calcaneal taping over windlass taping could be attributed to fact that greater weight bearing occurs on $c$ alcaneus during bilateral stance and taping support to calcaneus takes off major amount of stress and there by compressive load on plantar fascia reduces which results in lesser irritation, reduce in inflammation and better healing of micro tears. There are various limitations for this study, firstly the outcomes were measured immediately after the application of tape. The subjects were not asked about their functional ability. The duration of the patients symptoms were not taken into consideration, so the effect of chronicity was not considered. Therefore, studies testing the effects of these taping techniques in long durations are required. The foot functioning should be taken into account while looking into effects of these taping techniques. To get better accuracy, studies should take chronicity as compulsory inclusion criteria for selection of subjects.

\section{CONCLUSION}

In accordance to this study calcaneal taping provided better relief of symptoms with better biomechanical correction in short term. The calcaneal taping was much convenient and easy in terms of tape application and removal procedure when compared to windlass taping technique.

\section{Conflict of interest: None}

\section{REFERENCES}

1. Cornwall MW, McPoil TG. Plantar Fasciitis: Etiology and Treatment. Journal of Orthopaedic \& Sports Physical Therapy. 1999 Dec;29(12):756-60. Available from:

http://dx.doi.org/10.2519/jospt.1999.29.12.756.
Figure 4. Calcaneal taping

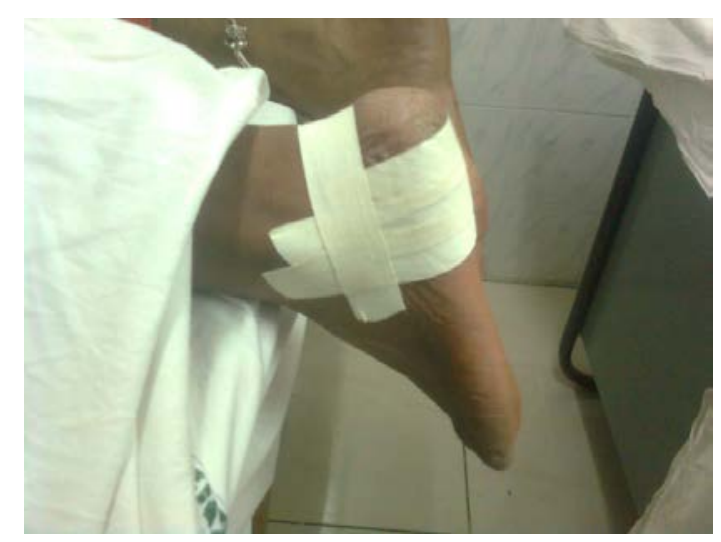

2. Lemont $\mathrm{H}$, Ammirati $\mathrm{KM}$, Usen $\mathrm{N}$. Plantar Fasciitis. Journal of the American Podiatric Medical Association. 2003 May; 93(3):234-7. Available from: http://dx.doi.org/10.7547/87507315-93-3-234.

3. Riddle DL, Pulisic $M$, Sparrow $K$, Impact of demographic and impairment-related variables on disability associated with plantar fasciitis. Foot Ankle Int2004;25:311-317.

4. Genova JM, Gross MT. Effect of Foot Orthotics on Calcaneal Eversion During Standing and Treadmill Walking for Subjects With Abnormal Pronation. Journal of Orthopaedic \& Sports Physical Therapy. 2000 Nov;30(11):664-75. Available from: http://dx.doi.org/10.2519/jospt.2000.30.11.664.

5. Gross MT. Semirigid orthoses position feet for plantarfasciitis relief. Biomech. 2001; 41.

6. McPoil TG, Martin RL, Cornwall MW, Wukich DK, Irrgang JJ, Godges JJ. Heel Pain-Plantar Fasciitis. Journal of Orthopaedic \& Sports Physical Therapy. 2008 Apr;38(4):A1-A18. Available from: http://dx.doi.org/10.2519/jospt.2008.0302.

7. Marks W, Jackiewicz A, Witkowski Z, Kot J, Deja W, Lasek J. Extracorporeal shock-wave therapy (ESWT) with a newgeneration pneumatic device in the treatment of heel pain. A double blind randomised controlled trial. Acta Orthop Belg.2008; 74: 98-101.

8. Roman Podolsky and Leonid Kalichman. Taping for plantar fasciitis. Journal of Back and Musculoskeletal Rehabilitation 28 (2015) 1-6

9. Jamali B, Walker M, Hoke B, Echternach J. Windlass taping technique for symptomatic relief of plantar fasciitis. J Sport Rehabil. 2004;13:228-243.

10. Matthew R. Hyland et al. Randomized Controlled Trial of Calcaneal Taping, Sham Taping, and Plantar Fascia Stretching for the Short-Term Management of Plantar 
Heel Pain. J Orthop Sports Phys Ther • Volume 36 • Number 6 • June 2006.

11. Jean Masse Genova et al. Effect of Foot Orthotics on Calcaneal Eversion During Standing and Treadmill Walking for Subjects With abnormal pronation. J Orthop Sports Phys Ther.Volume 30.Number 11 .November 2000.

12. Ayub A, Yale SH, Bibbo C. Common Foot Disorders. Clinical Medicine \& Research. 2005 May 1;3(2):116-9. Available from: http://dx.doi.org/10.3121/cmr.3.2.116.

13. Wearing SC, Smeathers JE, Sullivan PM, Yates B, Urry SR, Dubois P. Plantar Fasciitis: Are Pain and Fascial Thickness Associated With Arch Shape and Loading? Physical Therapy. 2007 Jun 6;87(8):1002-8. Available from: http://dx.doi.org/10.2522/ptj.20060136. 